\title{
Monitoring plant response to phenanthrene using the red edge of canopy hyperspectral reflectance
}

\author{
Linhai Zhu ${ }^{\mathrm{a}, \mathrm{b}}$, Zhongxin Chen ${ }^{\mathrm{c}}$, Jianjian Wang ${ }^{\mathrm{a}, \mathrm{d}}$, Jinzhi Ding ${ }^{\mathrm{e}, \mathrm{d}}$, Yunjiang Yu ${ }^{\mathrm{f}}$, Junsheng Li $^{\mathrm{f}}$, \\ Nengwen Xiao ${ }^{\mathrm{f}}$, Lianhe Jiang ${ }^{\mathrm{a}}$, Yuanrun Zheng ${ }^{\mathrm{a}, *}$, Glyn M. Rimmington ${ }^{\mathrm{g}}$ \\ ${ }^{a}$ Key Laboratory of Plant Resources, Beijing Botanical Garden, West China Subalpine Botanical Garden, Institute of Botany, Chinese Academy of Sciences, Beijing 100093, China \\ ${ }^{\mathrm{b}}$ State Key Laboratory of Urban and Regional Ecology, Research Center for Eco-Environmental Sciences, Chinese Academy of Sciences, Beijing 100085, China

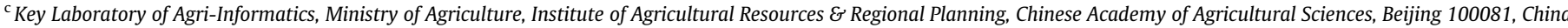 \\ ${ }^{\mathrm{d}}$ University of Chinese Academy of Sciences, Beijing 100049, China \\ e State Key Laboratory of Vegetation and Environmental Change, Institute of Botany, Chinese Academy of Sciences, Beijing 100093, China \\ ${ }^{\mathrm{f}}$ Chinese Research Academy of Environmental Sciences, Beijing 100012, China \\ ${ }^{\mathrm{g}}$ Global Learning Office, College of Liberal Arts E Sciences, Wichita State University, Wichita, KS 67260-0142, United States
}

\section{A R T I C L E I N F O}

\section{Article history:}

Available online 16 July 2014

\section{Keywords:}

Remote sensing

Oil pollution

Polycyclic aromatic hydrocarbons

Field canopy spectroscopy

Hyperspectral

Oil spill

\begin{abstract}
A B S T R A C T
To investigate the mechanisms and potential for the remote sensing of phenanthrene-induced vegetation stress, we measured field canopy spectra, and associated plant and soil parameters in the field controlled experiment in the Yellow River Delta of China. Two widely distributed plant communities, separately dominated by reed (Phragmites australis) and glaucous seepweed (Suaeda salsa), were treated with different doses of phenanthrene. The canopy spectral changes of plant community resulted from the decreases of biomass and foliar projective coverage, while leaf photosynthetic pigment concentrations showed no significance difference among treatments. The spectral response to phenanthrene included a flattened red edge, with decreased first derivative of reflectance. The red edge slope and area consistently responded to phenanthrene, showing a strong relationship with aboveground biomass, coverage and canopy pigments density. These results suggest the potential of remote sensing and the importance of field validation to correctly interpret the causes of the spectral changes.
\end{abstract}

(c) 2014 Elsevier Ltd. All rights reserved.

\section{Introduction}

The monitoring of vegetation status under pollution is an important issue attracting attention from researchers, environmental regulators and legislators (Lin and Mendelssohn, 2012; Mishra et al., 2012). The monitoring of affected vegetation uses various methods such as sampling and chemical analysis of the soil, water, air and plants (Manzo et al., 2013; Nascimbene et al., 2014). However, these ground-based methods are time-consuming and expensive, especially when they are applied to large areas ( Wu et al., 2005; Yi et al., 2007; Fauzi et al., 2013). Airborne or spaceborne remote sensing can simultaneously monitor relatively large areas quickly in a non-destructive fashion and could be integrated with a field-based approach, improving monitoring ability (Ayanu et al., 2012; Hunter et al., 2009).

Environmental pollution affects plant physiology and growth such as biomass (Rosso et al., 2005; Splajt et al., 2003; Zhu et al.,

\footnotetext{
* Corresponding author. Tel.: +86 1062836508.

E-mail address: zhengyr@ibcas.ac.cn (Y. Zheng).
}

2013) and chlorophyll content (Mishra et al., 2012; Newete et al., 2014). These parameters are closely related to the change in the canopy reflectance spectra (Rosso et al., 2005; Splajt et al., 2003; Zhu et al., 2013). Therefore, remote sensing can characterize vegetation stress by recording the spectral signals of plants growing in the polluted environment (Kooistra et al., 2004; Zhu et al., 2013). Under metal and air pollution, the strong correlation is observed between the spectral changes and leaf chlorophyll concentrations (Newete et al., 2014; Splajt et al., 2003). However, many factors control the variation of leaf and canopy reflectance. At the leaf level, water contents, morphological and anatomical properties, and other biochemical components also explain the change of spectral signals (Ullah et al., 2012). At the canopy level, the green biomass, coverage, leaf area index (LAI) and canopy architecture can predict the canopy reflectance of plants (Zhu et al., 2013; Zhang et al., 2014). The existence of different factors affecting vegetation reflectance implies that there are multiple mechanisms linking environmental pollution, plant responses and spectral changes. In order to correctly interpret the information provided by the remote sensors, these mechanisms should be further 
explored using detail spectral signals obtained at the different scales including canopy (Rosso et al., 2005).

Hyperspectral sensors detect signals of hundreds of contiguous spectral bands $<10 \mathrm{~nm}$ within the visible and near-infrared spectrum (Goetz et al., 1985; Yi et al., 2007). Therefore, hyperspectral sensors can collect information that traditional multispectral sensors cannot. Its powerful information collection makes hyperspectral sensors ideal for measuring the Red Edge of canopy reflectance (Cho and Skidmore, 2006; Horler et al., 1983). Red edge is a sharp increase from the low red reflectance to the high infrared reflectance caused by chlorophyll absorption at ca. $680 \mathrm{~nm}$ and internal leaf scattering near $750 \mathrm{~nm}$ (Horler et al., 1983). The spectral information of the red edge provides a foundation for the further analysis of spectra including the calculation of vegetation indices, which is widely used by the airborne and spaceborne remote sensing (Zhu et al., 2013). When monitoring vegetation pollution, early studies investigating red edge identified the wavelength corresponding to the maximum first derivative of reflectance. This wavelength is defined as the Red Edge Position (REP) or Red Edge Inflection Point (REIP) (Splajt et al., 2003; Ustin et al., 2009). However, the Red Edge Slope (RES) and Area (REA), defined as the maximum of the first derivative and the area under the derivative curve in the region of red edge remains less well studied, because the calculation of these two parameters requires information of high spectral resolution.

The shift of the red edge position is associated with heavy metal pollution in soils (Kooistra et al., 2004; Splajt et al., 2003) and air pollution (Manzo et al., 2013). However, organic pollutants in soils have been rarely studied using the red edge. This study focused on Polycyclic Aromatic Hydrocarbons (PAHs), a class of widely distributed hazardous organic chemicals with a long-term persistence in ecosystems (Nascimbene et al., 2014). PAHs also have detrimental biological effects such as mutagenicity and carcinogenicity (Gan et al., 2009; Haritash and Kaushik, 2009; Camacho et al., 2012). Therefore, we investigated the change in the red edge using phenanthrene as the pollutant, evaluating changes of red edge slope and area as indictors of vegetation stress and exploring the mechanism of spectral changes.

Hydrocarbon pollution has increased in the Yellow River Delta of eastern China due to intensive oil extraction (Nie et al., 2009; Wang et al., 2011; Yu et al., 2012). The extent and severity of this hydrocarbon pollution needs to be quantified to avoid further damage to this ecosystem. The delta is a typical littoral wetland ecosystem, harboring many plant species such as reed (Phragmites australis) and glaucous seepweed (Suaeda salsa) (Nie et al., 2009; Yu et al., 2012; Zhu et al., 2013). This field study dosed two widely distributed types of plant communities, separately dominated by reed and seepweed, with four different levels of phenanthrene to investigate the biophysical mechanisms and the potential of red edge change (blue shift) to monitor plant response to phenanthrene at the canopy level.

\section{Material and methods}

\subsection{Experimental design}

To avoid hydrocarbon pollution, we conducted the experiment away from oil production areas $\left(37^{\circ} 51^{\prime} \mathrm{N}, 118^{\circ} 33^{\prime} \mathrm{E}\right)$ in the Yellow River Delta from May to August 2010. We selected two plant communities, dominated by reed ( $P$. australis) and seepweed ( $S$. salsa), respectively. These two plant communities are widely distributed in the Yellow River Delta (Nie et al., 2011; Yu et al., 2012; Zhu et al., 2013), with a simple community structure and composition (Fig. 1A-B). During May 2010, four levels of phenanthrene were applied in each plant community type, each level replicated three times. These levels were: $0 \mathrm{~g} \mathrm{~m}^{-2}$ (the control, $\mathrm{C}$ treatment); $0.125 \mathrm{~g} \mathrm{~m}^{-2}$ (L treatment); $1.25 \mathrm{~g} \mathrm{~m}^{-2}$ (M treatment); $12.5 \mathrm{~g} \mathrm{~m}^{-2}$
( $\mathrm{H}$ treatment). We established 24 plots of $2 \mathrm{~m} \times 2 \mathrm{~m}$, which were divided into 6 groups. Every group that consisted of four different treatments was arranged in a homogeneous plant community, and the treatments were properly distributed to avoid cross-contamination. Before treatment application, a $60 \mathrm{~cm}$-deep ditch was dug around each plot to enable the plots to be wrapped with polyethylene (Fig. 1A). This operation isolated the plots horizontally from the surrounding soils, ensuring the containment of phenanthrene within the plots. The ditches were backfilled with the soil. Phenanthrene used in each treatment was dissolved in $3 \mathrm{~L}$ of acetone and sprayed over each plot. The control was sprayed by only three liters of acetone. The spray method simulated the scenario of oil spill causing PAHs pollution.

\subsection{Survey before phenanthrene application}

To validate the field experiment, we measured the following parameters before treatment application.

\subsubsection{Phenanthrene pollution}

Four soil samples (30 cm deep) from each of the four sides of the plots were collected for phenanthrene analysis during plot preparation. Phenanthrene concentrations were measured using GC/MS according to the method 8270D developed by the United States Environmental Protection Agency (2007).

\subsubsection{Plant parameters}

The plant parameters were measured in the center of each plot ( $1 \mathrm{~m} \times 1 \mathrm{~m}$ area). These two species provided above 95\% of biomass in their own communities (Fig. 1A-B). Therefore, we recorded plant height, live stem density and coverage only for these two species. From 30 stems of reeds in each plot we measured the number of leaves, their width and length. The leaves of seepweeds were very small at that time (Fig. 1B). Therefore, we did not record their leaf parameters.

\subsection{Survey following the addition of phenanthrene}

Three months (August) after the treatment, the following parameters were measured in the $1 \mathrm{~m} \times 1 \mathrm{~m}$ central area of plots.

\subsubsection{Plant parameters}

As shown in Fig. 1C-J, there scarcely existed other species in the two types of plant communities. Therefore, we measured plant parameters only for reed and seepweed. Using 10 randomly selected reeds, we measured leaf chlorophyll concentration (SPAD-502, Konica Minolta Sensings Inc., Osaka, Japan) on the widest part of a fully expanded leaf (Mishra et al., 2012). The SPAD-502 measures chlorophyll concentrations in a range from -9.9 to 199.9 SPAD units, with an accuracy of \pm 1.0 SPAD units (Konica Minolta Sensing Inc., 2003). The leaves of seepweeds are thick, and SPAD502 cannot be used to measure their chlorophyll concentration. Therefore, three leaf samples from seepweed per plot were sampled to analyze chlorophyll a and b as well as total carotenoid concentrations using the procedure described by Lichtenthaler (1987). The leaf total chlorophyll concentrations of seepweed were the sum of leaf chlorophyll a and b concentrations.

The coverage of plant community was visually estimated. The number of live stem was counted to determine live stem density of two plants. The mortality was calculated as follow:

$$
\frac{L S D_{\text {May }}-L S D_{\text {Aug }}}{L S D_{\text {May }}} \times 100 \%
$$

where $L S D_{\text {May }}$ and $L S D_{\text {Aug }}$ is the live stem density in May and August, respectively. 


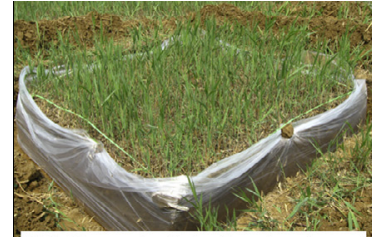

(A) $P$. australis before treatment
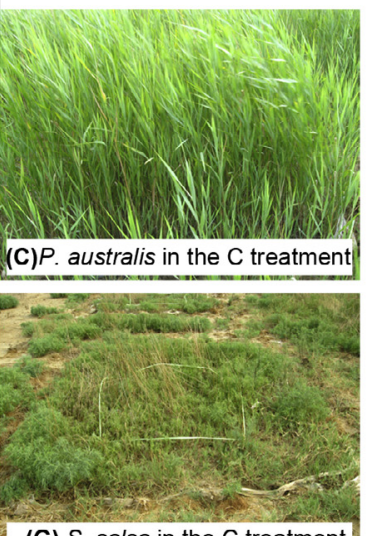

(G) S. salsa in the C treatment

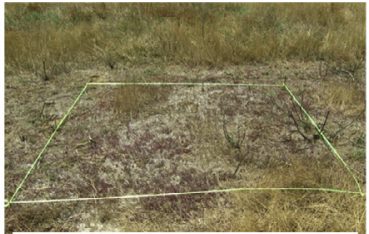

(B) S. salsa before treatment
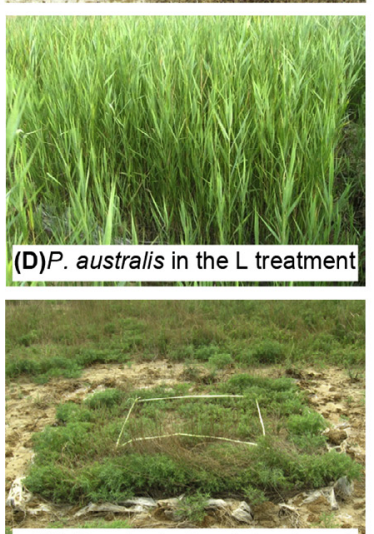

(H) S. salsa in the L treatment
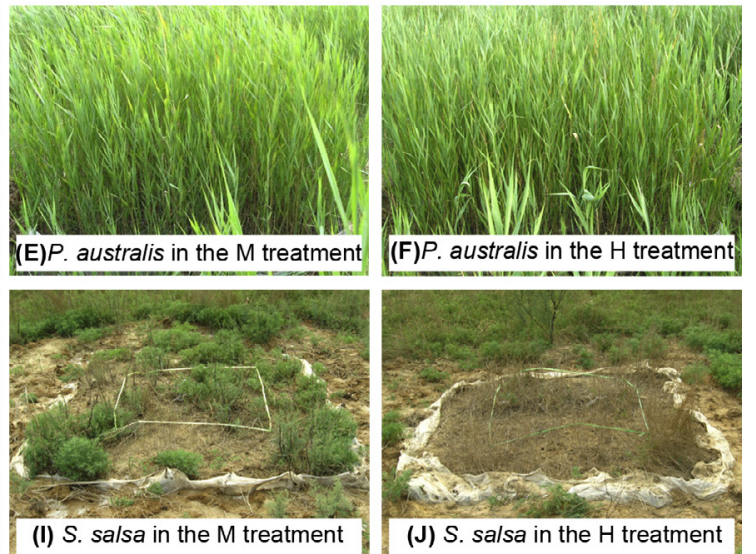

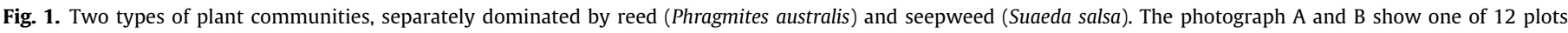

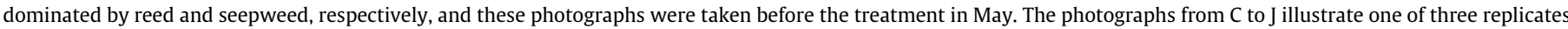

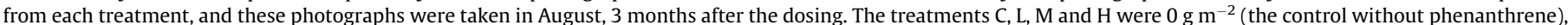
$0.125 \mathrm{~g} \mathrm{~m}^{-2}, 1.25 \mathrm{~g} \mathrm{~m}^{-2}$ and $12.5 \mathrm{~g} \mathrm{~m}^{-2}$, respectively.

We harvested the aboveground plant biomass from a $50 \mathrm{~cm} \times 50 \mathrm{~cm}$ area in the plots. The aboveground parts were separated into stem and leaf components, dried at $80^{\circ} \mathrm{C}$ for $72 \mathrm{~h}$ and weighed. We calculated aboveground biomass as the sum of stem and leaf dry weight.

The fresh weight of the leaf component was weighed to calculate canopy photosynthetic pigment densities. The canopy pigment densities were calculated as the product of fresh leaf weight and pigment concentrations (Broge and Leblanc, 2000).

\subsubsection{Reflectance spectra of the community canopy}

The reflectance spectra for each plot were recorded using a field spectroradiometer ASD FieldSpec FR (Analytical Spectral Devices Inc., Boulder, CO, USA). This spectroradiometer was fitted with a fiber optic probe having a $25^{\circ}$ field of view. It covers the spectrum between $350 \mathrm{~nm}$ and $2500 \mathrm{~nm}$ and its spectral sampling interval is $1.4 \mathrm{~nm}$ for the region $350-1000 \mathrm{~nm}$ and $2 \mathrm{~nm}$ for the region 1000 $2500 \mathrm{~nm}$. Its spectral resolution (full-width-half-maximum) is $3 \mathrm{~nm}$ for the region $350-1000 \mathrm{~nm}$ and $10 \mathrm{~nm}$ for the region $1000-2500 \mathrm{~nm}$. The spectra were then interpolated by the ASD software to produce readings at every $1 \mathrm{~nm}$. Measurements were taken between 10:00 and 12:00 am on clear days without clouds and winds. Scans were taken from a height of $50 \mathrm{~cm}$ above the canopies of the plant communities looking towards the nadir position so that the field of view was a circular area having a diameter of about $22 \mathrm{~cm}$ (Zhu et al., 2013). Ten reflectance spectra of bare soils were recorded at each of three locations adjacent to the two plant communities. We measured the spectra of plant communities from the $C$ treatment first, then the $L$ and $M$ treatment, and finally the $H$ treatment. This procedure was repeated six times. Ten spectra were recorded from five equidistant points on each diagonal of the $1 \mathrm{~m} \times 1 \mathrm{~m}$ square in the center of each plot. The two points at the two ends of each diagonal were located at the vertices of the square. Before the measurement of each points, the radiance of a white standard panel coated with $\mathrm{BaSO}_{4}$ and the dark current (Systematic noise from the instrument electronics and detectors) were recorded for reference and optimization of measurement. Because the energy incident on plant or soil is approximately equivalent to that reflected by the white panel, the reflectance $(\rho, \%)$ can be calculated as follows.

$\rho=\frac{\text { target }- \text { darkcurrent }}{\text { reference }- \text { darkcurrent }} \times 100 \%$

where 'target' is the energy reflected off plant canopies or bare soils, and 'reference' is that reflected off $\mathrm{BaSO}_{4}$ white panel (Zhu et al., 2013).

After the individual reflectance spectra were inspected for incorrect data and outliers, plot data means were calculated. For calculating the first derivatives of the averaged reflectance values, the smallest derivative gap (3) in ViewSpec Pro $^{\mathrm{TM}}$ was selected to avoid masking narrow absorption features (Mitchell et al., 2012). Then the first derivatives were employed to obtain red edge slope (maximum) and area (integral) between 680 and $750 \mathrm{~nm}$ (Zhu et al., 2013).

\subsubsection{Residual phenanthrene in soils}

Five samples ( $0-30 \mathrm{~cm}$ deep) were collected using an auger from the five equidistant points on the diagonal of a $1 \mathrm{~m} \times 1 \mathrm{~m}$ square at the center of each plot. The two points at the two ends of the diagonal were located at the vertices of the square. The five samples were mixed for phenanthrene analysis using the GC/MS method 8270D (United States Environmental Protection Agency, 2007).

\subsection{Statistical analysis}

For each species, the values of each treatment including its three controls were standardized to the mean of the controls. The mean of the controls was set as $100 \%$. This transformation maintained the original distribution of the data and facilitated a direct comparison of two plant species' difference (Lin and Mendelssohn, 2012). This transformation also eliminated the 
Table 1

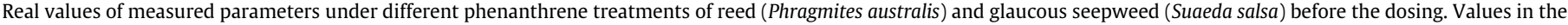
table were means \pm standard errors.

\begin{tabular}{|c|c|c|c|c|c|c|c|}
\hline Species & $\begin{array}{l}\text { Phenanthrene } \\
\text { treatment }\end{array}$ & $\begin{array}{l}\text { Plant height } \\
(\mathrm{cm})\end{array}$ & $\begin{array}{l}\text { Live stem density (stem } \\
\mathrm{m}^{-2} \text { ) }\end{array}$ & $\begin{array}{l}\text { Foliar projective } \\
\text { coverage }(\%)\end{array}$ & $\begin{array}{l}\text { Leaf } \\
\text { number }\end{array}$ & $\begin{array}{l}\text { Leaf width } \\
(\mathrm{cm})\end{array}$ & $\begin{array}{l}\text { Leaf length } \\
(\mathrm{cm})\end{array}$ \\
\hline Reed (Phragmites australis) & $\begin{array}{l}\mathrm{C}\left(0.000 \mathrm{~g} \mathrm{~m}^{-2}\right) \\
\mathrm{L}\left(0.125 \mathrm{~g} \mathrm{~m}^{-2}\right) \\
\mathrm{M}\left(1.250 \mathrm{~g} \mathrm{~m}^{-2}\right) \\
\mathrm{H}\left(12.50 \mathrm{~g} \mathrm{~m}^{-2}\right)\end{array}$ & $\begin{array}{l}54.89 \pm 4.56 \\
52.56 \pm 4.88 \\
57.56 \pm 4.45 \\
55.67 \pm 5.23\end{array}$ & $\begin{array}{l}318.67 \pm 40.68 \\
329.33 \pm 22.43 \\
328.00 \pm 28.00 \\
348.00 \pm 37.17\end{array}$ & $\begin{array}{l}6.00 \pm 0.58 \\
5.67 \pm 0.67 \\
6.17 \pm 0.60 \\
6.17 \pm 1.09\end{array}$ & $\begin{array}{l}3.66 \pm 0.33 \\
3.67 \pm 0.19 \\
3.67 \pm 0.00 \\
3.67 \pm 0.38\end{array}$ & $\begin{array}{l}1.12 \pm 0.05 \\
1.10 \pm 0.03 \\
1.18 \pm 0.01 \\
1.10 \pm 0.04\end{array}$ & $\begin{array}{l}13.92 \pm 0.74 \\
13.31 \pm 0.33 \\
13.72 \pm 0.60 \\
12.97 \pm 0.19\end{array}$ \\
\hline $\begin{array}{l}\text { Glaucous seepweed } \\
\quad \text { (Suaeda salsa) }\end{array}$ & $\begin{array}{l}\mathrm{C}\left(0.000 \mathrm{~g} \mathrm{~m}^{-2}\right) \\
\mathrm{L}\left(0.125 \mathrm{~g} \mathrm{~m}^{-2}\right) \\
\mathrm{M}\left(1.250 \mathrm{~g} \mathrm{~m}^{-2}\right) \\
\mathrm{H}\left(12.50 \mathrm{~g} \mathrm{~m}^{-2}\right)\end{array}$ & $\begin{array}{l}3.67 \pm 1.20 \\
3.00 \pm 0.58 \\
2.67 \pm 0.33 \\
3.00 \pm 0.58\end{array}$ & $\begin{array}{l}844.00 \pm 231.80 \\
836.00 \pm 240.41 \\
848.00 \pm 229.83 \\
885.33 \pm 295.94\end{array}$ & $\begin{array}{l}3.67 \pm 1.45 \\
1.77 \pm 0.87 \\
2.00 \pm 1.01 \\
2.40 \pm 0.95\end{array}$ & & & \\
\hline
\end{tabular}

effects of different methods of leaf total chlorophyll concentration for two plant species. The real values for different treatments before and after the dosing were presented in the Tables 1 and 2 . respectively. In this study, some parameters were measured for both of two species, and other parameters (for example, chlorophyll $\mathrm{a}$ and $\mathrm{b}$ concentrations) were measured only for one species. General Linear Model in SAS (SAS Institute Inc., Cary, NC, USA) was used to analyze the treatment difference of the parameters measured on the two species. One-Way Analysis of Variance in IBM SPSS (SPSS Inc., Chicago, IL, USA) was employed to test the treatment difference of the parameters measured only for one species. Both General Linear Model and One-Way Analysis of Variance determine the significance of difference based on $F$ values. General linear model calculate $F$ values for the established model, the main effects of phenanthrene treatment and species, and their interaction. The relationships between spectral and plant parameters were established using Curve Estimation (SPSS). Figures were drawn using Adobe Photoshop CS4 (Fig. 1, Adobe Systems Inc., San Jose, CA, USA) and were plotted using OriginPro 8.5.1 (Figs. 29, OriginLab Corporation, Northampton, MA, USA).

\section{Results}

\subsection{Analysis before the addition of phenanthrene}

The soil samples showed no presence of phenanthrene prior to treatment application $\left(<1.0 \mu \mathrm{g} \mathrm{kg}^{-1}\right)$. For two species, plant height (established model: $F_{7,16}=0.57, p=0.768$ ), live stem density (established model: $F_{7,16}=0.02, p=0.999$ ) and coverage (established model: $\left.F_{7,16}=1.05, p=0.439\right)$ showed no significant differences (Table 1). For reed, leaf number $\left(F_{3,8}=0.00, p=0.998\right)$, width $\left(F_{3,8}=0.98, p=0.450\right)$ and length $\left(F_{3,8}=0.66, p=0.597\right)$ showed no significant differences (Table 1$)$. These pre-experimental tests ensured the integrity of this field experiment.

\subsection{Residual soil phenanthrene after 3 months}

Phenanthrene concentrations in the soil samples (Fig. 2, Table 2) significantly differed with the phenanthrene treatment $\left(F_{3,16}=194.50^{1}, \quad p<0.0001\right)$, plant communities $\left(F_{1,16}=217.93\right.$, $p<0.0001)$, and their interaction $\left(F_{3,16}=191.45, p<0.0001\right)$. Phenanthrene concentrations in the treatment $\mathrm{H}$ of seepweed community were significantly higher compared with other treatments $(p<0.0001)$. Phenanthrene concentrations in all treatments of reed community showed no significant differences ( $p>0.855$, Fig. 2). The very high concentrations of residual phenanthrene in treatment $\mathrm{H}$ of seepweed community with few plants (Figs. 1J, 2) excluded the

1 If not specified, $F$ values from the General Linear models belong to the main effects of phenanthrene treatment or species, or their interaction. possibility of complete depletion of phenanthrene by natural attenuation.

\subsection{Plant response to phenanthrene}

Live stem density (Figs. 1C-J, 3A, Table 2) significantly differed with phenanthrene treatment $\left(F_{3,16}=5.11, p<0.01\right)$, species $\left(F_{1,16}=42.72, \quad p<0.0001\right)$, and their interaction $\left(F_{3,16}=6.66\right.$, $p=0.004)$. The live stem density of seepweed was significantly affected by phenanthrene compared with reed. Live stem density of seepweed in the $\mathrm{M}$ and $\mathrm{H}$ treatments were significantly lower compared with the control, and the density of its $\mathrm{H}$ treatments were significantly lower than that of its L treatment. However, live stem densities of reed in all treatments were not significantly different. Decreased live stem density in seepweed may be attributed to the increase of plant mortality induced by phenanthrene (Fig. 4). The mortality of seepweed in the $\mathrm{M}$ and $\mathrm{H}$ treatments was significantly higher compared with the control and $\mathrm{L}$ treatment $\left(F_{3,8}=13.294, p=0.002\right.$; Fig. 4$)$.

Plant coverage (Figs. 1C-J, 3B, Table 2) significantly differed with phenanthrene treatment $\left(F_{3,16}=4.29, p=0.021\right)$ and plant community $\left(F_{1,16}=7.14, p=0.017\right)$, but not their interaction $\left(F_{3,16}=1.03, p=0.405\right)$. Phenanthrene affected the coverage of seepweed community significantly compared with reed community. The coverage of seepweed community in the $\mathrm{M}$ and $\mathrm{H}$ treatments was significantly lower compared with the control, and the coverage of its $\mathrm{H}$ treatment was significantly lower that of its $\mathrm{L}$ treatment. The coverage of reed community showed a negative association with increasing phenanthrene concentrations. However, the coverage of reed community showed no significant differences across all the treatments.

Aboveground biomass (Figs. 1C-J, 3C, Table 2) significantly differed with phenanthrene treatment $\left(F_{3,16}=4.27, p=0.022\right)$ and species $\left(F_{1,16}=9.09, p=0.008\right)$, but not their interaction $\left(F_{3,16}=1.81, \quad p=0.185\right)$. Phenanthrene affected aboveground biomass of seepweed more than that of reed. The aboveground biomass of seepweed in the $\mathrm{L}(p=0.053), \mathrm{M}(p=0.006)$ and $\mathrm{H}$ $(p=0.002)$ treatments was significantly lower compared with the control. However, the aboveground biomass of reed among all the treatments showed no significant differences.

Reed and seepweed showed no significant difference in leaf total chlorophyll concentration (established model: $F_{7,16}=1.59$, $p=0.210$ ), and seepweed showed no significant difference in leaf chlorophyll a $\left(F_{3,8}=1.83, p=0.220\right)$ and $\mathrm{b}\left(F_{3,8}=2.10, p=0.179\right)$, and carotenoids $\left(F_{3,8}=0.86, p=0.501\right)$ concentrations (Table 2$)$. The canopy photosynthetic pigment density of seepweed (Fig. 5, Table 2), including chlorophyll a $\left(F_{3,8}=7.29, p=0.011\right)$ and $\mathrm{b}$ $\left(F_{3,8}=5.38, p=0.025\right)$, total chlorophyll $\left(F_{3,8}=6.61, p=0.015\right)$ and carotenoids $\left(F_{3,8}=4.61, p=0.037\right)$, decreased significantly with increasing phenanthrene levels. The canopy pigment density of seepweed in the $\mathrm{L}, \mathrm{M}$ and $\mathrm{H}$ treatments was significantly lower compared with the control. 


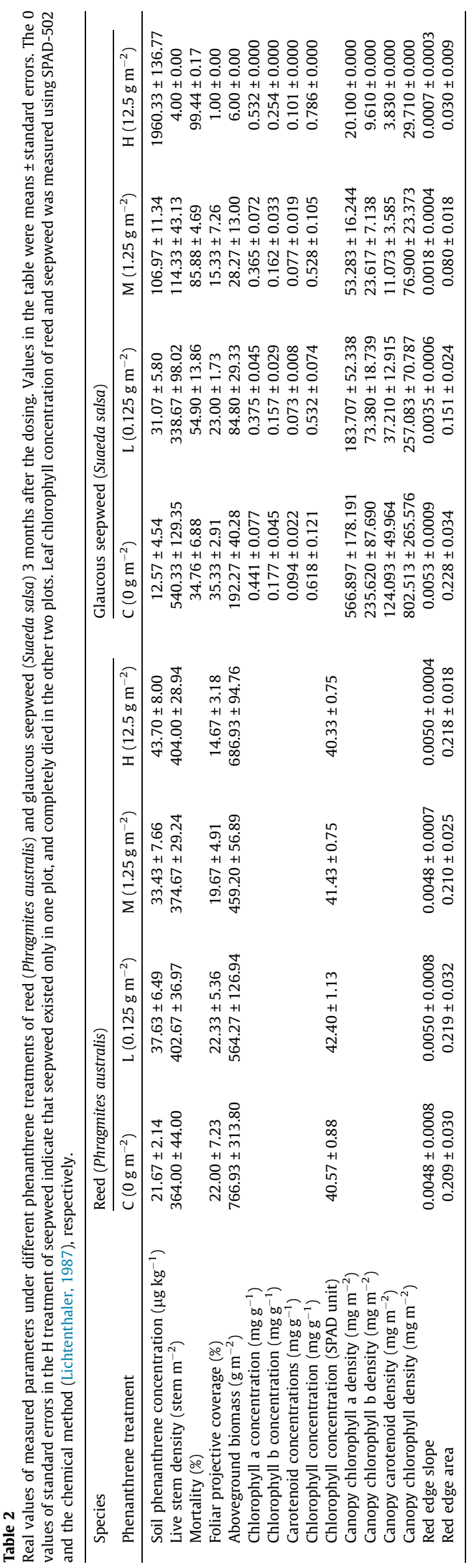

\subsection{Spectral properties of the community canopy}

The canopy reflectance of reed community (Fig. 6A) and its first derivative (Fig. 6C) showed no significant differences among phenanthrene treatments, whereas the reflectance of seepweed community (Fig. 6B) and its first derivative (Fig. 6D) showed significant differences among phenanthrene treatments. For seepweed community, increasing phenanthrene concentrations showed a positive association with reflectance at $680 \mathrm{~nm}$. However, the reflectance at $680 \mathrm{~nm}$ in treatment $M$ was only slightly greater than that in treatment L. The control showed the largest reflectance at $750 \mathrm{~nm}$, followed by the $\mathrm{L}$ treatment. The reflectance at $750 \mathrm{~nm}$ from treatment $\mathrm{M}$ was smaller compared with treatment $\mathrm{H}$. The spectral curve of the treatment $\mathrm{H}$ was similar to that of bare soil (Fig. 6B). The reflectance of seepweed community at $680 \mathrm{~nm}$ showed a significant negative association with canopy chlorophyll density (Fig. 7A). However, the reflectance of seepweed community at $750 \mathrm{~nm}$ showed no significant association with aboveground biomass (Fig. 7B). The increased level of phenanthrene flattened the red edge of seepweed community and lowered its first derivative of reflectance (Fig. 6D), indicating a decrease in red edge slope and area. There were three peaks located at approximately $700 \mathrm{~nm}, 717 \mathrm{~nm}$ and $723 \mathrm{~nm}$ in the red edge region (Fig. 6D).

Red edge slope (RES) and area (REA) (Fig. 8, Table 2) significantly differed with phenanthrene treatment (for RES: $F_{3,16}=4.11, p=0.024$; for REA: $F_{3,16}=5.04, p=0.012$ ), plant communities (for RES: $F_{1,16}=29.92, p<0.0001$; for REA: $F_{1,16}=34.89$, $p<0.0001$ ), and their interaction (for RES: $F_{3,16}=4.82, p=0.014$; for REA: $F_{3,16}=5.50, p=0.009$ ). Phenanthrene affected the RES and REA of seepweed community more than these of reed community. The RES and REA of seepweed community in treatments $M$ $(p=0.002, p=0.001)$ and $\mathrm{H}(p=0.0002, p<0.0001)$ were significantly smaller compared with the control, and the RES and REA of its $\mathrm{H}$ treatment were significantly smaller than those of its L treatment. However, the RES and REA of reed community across all the treatments showed no significant differences. The RES and REA of seepweed community were significantly and positively associated with aboveground biomass, coverage and canopy pigment density of seepweed (Fig. 9 and Supplementary data). No correlation was observed between the canopy spectral changes and leaf pigment concentrations of seepweed.

\section{Discussion}

\subsection{Effects on plant parameters of two dominant plants}

Different plant species have dissimilar sensitivities to pollutants. Seepweed is more sensitive to oil hydrocarbons in the soil compared with reed in a simulated oil contamination experiment (Yu et al., 2012). Our study demonstrated that phenanthrene affected seepweed more severely than reed. Annual plants are generally more sensitive to hydrocarbon pollution compared with perennials (Pezeshki et al., 2000). Seepweed and reed are annual and perennial plants, respectively, and reed emerges earlier than seepweed (Fig. 1A-B). This may explain: (1) the higher sensitivity in seepweed compared with reed; and (2) how reed having larger stems and more leaves showed a higher tolerance to phenanthrene than seepweed (Fig. 1A-B).

Plants can recover by producing new leaves after hydrocarbon pollution (Lin and Mendelssohn, 2012; Judy et al., 2014), as confirmed in this study with reed and seepweed (Fig. 1C-J). For seepweed, the addition of phenanthrene led to the increase of mortality (Fig. 4) and the decrease of live stem density (Fig. 3A). However, the remains of seepweed finally recovered and grew well without 


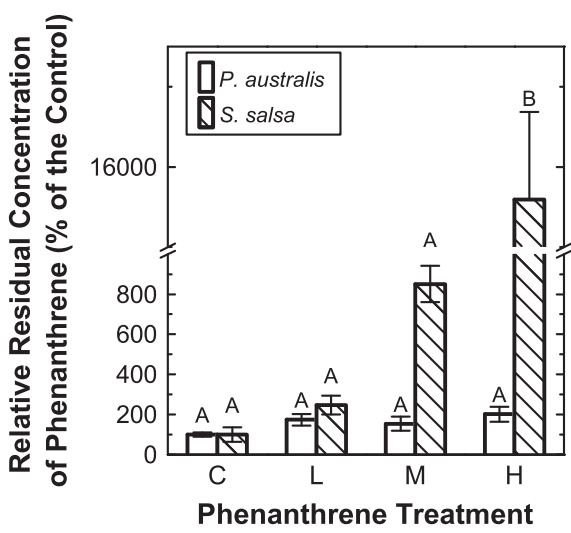

Fig. 2. Residua of phenanthrene $( \pm \mathrm{SE}$ ) in soils 3 months after the addition. Each bar represents the mean of three replicates, bars with different capital letters are significantly different from each other $(p<0.01)$. Other descriptions are the same as Fig. 1. The real values are presented in Table 2.
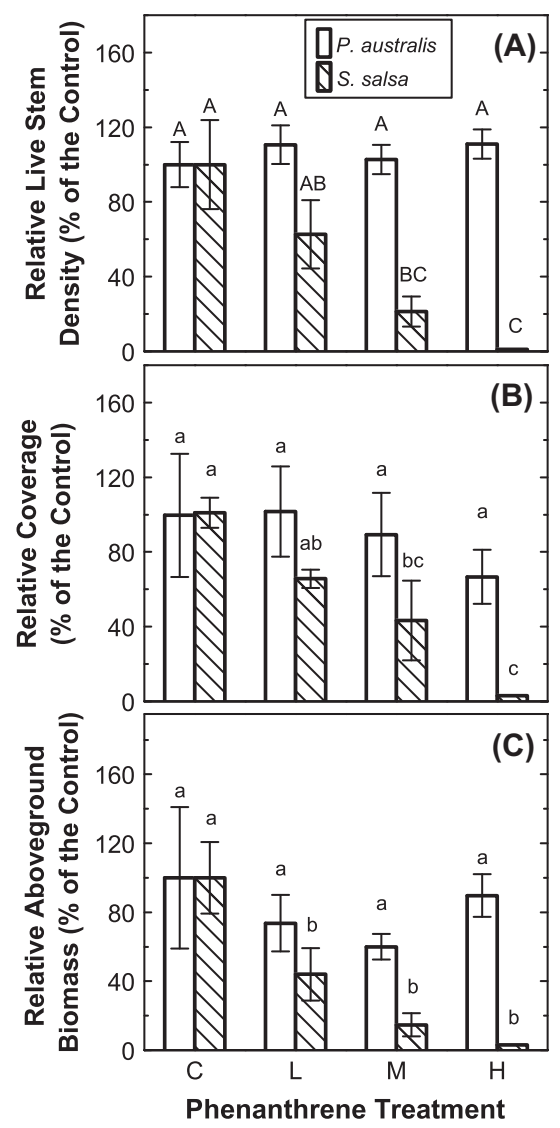

Fig. 3. Effects of phenanthrene on the live stem density (A), foliar projective coverage (B) and aboveground biomass (C) of Phragmites australis and Suaeda salsa. The values are means \pm standard errors $(n=3)$. The capital and lower-case letters above the bars indicate the significant differences at the level of 0.01 and 0.05 . If the letters or one of letters assigned to bars was the same, there is no significant difference between corresponding treatments. If the letters was completely different, a significant deference exists between corresponding treatments. Other descriptions are the same as Fig. 1. The real values are presented in Table 2.

leaf chlorosis (Fig. 1G-J) and the decrease of leaf photosynthetic pigment concentrations (Table 2). Therefore, the decreased canopy pigment density in this study was the result of decreased biomass, which was associated with the increased mortality. Our result is different from some previous studies relating the decreased leaf pigment concentrations to the effects of pollution (Rosso et al., 2005; Newete et al., 2014).

The presence of phenanthrene gradient in the seepweed community, especially the very high residual concentration of phenanthrene in its $\mathrm{H}$ treatment with few plants (Figs. 1J, 2) excluded the possibility of complete depletion of phenanthrene by natural attenuation. However, there was no phenanthrene gradient in reed communities 3 months after the treatment. This result could be explained by the phytoremediation of reed and associated microbes. For phytoremediation of PAHs, plants from Gramineae are used as this family contains plants with very fibrous root systems, which extend over a large surface area and have deep soil penetration (Gan et al., 2009). Reed, with an extensive root system and clonal propagation value, showed good potential in the phytoremediation of phenanthrene in combination of associated microbes (Nie et al., 2011).

\subsection{Mechanisms and potential for monitoring plant stress using the red edge}

In this study, no chlorosis was observed in the leaves of two species (Fig. 1C-J) and there was no significant difference in leaf pigment concentrations among treatments. Therefore, the spectral changes were not associated with the variation of photosynthetic pigment concentrations in leaves, and these changes were strongly related to biomass, coverage and canopy photosynthetic pigment density (Fig. 9 and Supplementary material). The changes of biomass and coverage mediated the relationship between spectral changes and canopy pigment density. This result is different from the previous studies that observe a strong relationship between the spectral changes and leaf chlorophyll concentrations under metal and air pollution (Splajt et al., 2003; Newete et al., 2014). In previous studies, the biomass and leaf chlorophyll concentrations together contribute to the spectral changes. These results suggested that the mechanism for the spectral changes may vary with the type of pollutants, the degree of pollution, the tolerance of plant, and the time after exposure. These diverse causes for spectral changes under environmental stresses necessitate the field validation of image interpretation. Combing field survey with the airborne and spaceborne remote sensing could give more accurate explain and monitoring of vegetation changes under pollution.

The canopy red reflectance is governed by the light absorption of chlorophyll; the decreased red reflectance is associated with the increase of canopy chlorophyll concentrations. The greatest reflectance contrast between plants and soil occurs in the red spectral region (Thenkabail et al., 2004), while chlorophyll variation at leaf or canopy level is stress sensitive (Knipling, 1970). Therefore,

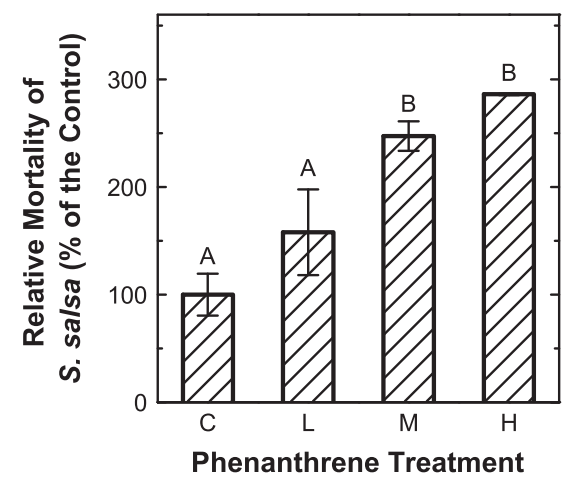

Fig. 4. Effect of phenanthrene on the mortality of Suaeda salsa. The values are means \pm standard errors $(n=3)$. Other descriptions are the same as Fig. 3 . The real values are presented in Table 2 . 

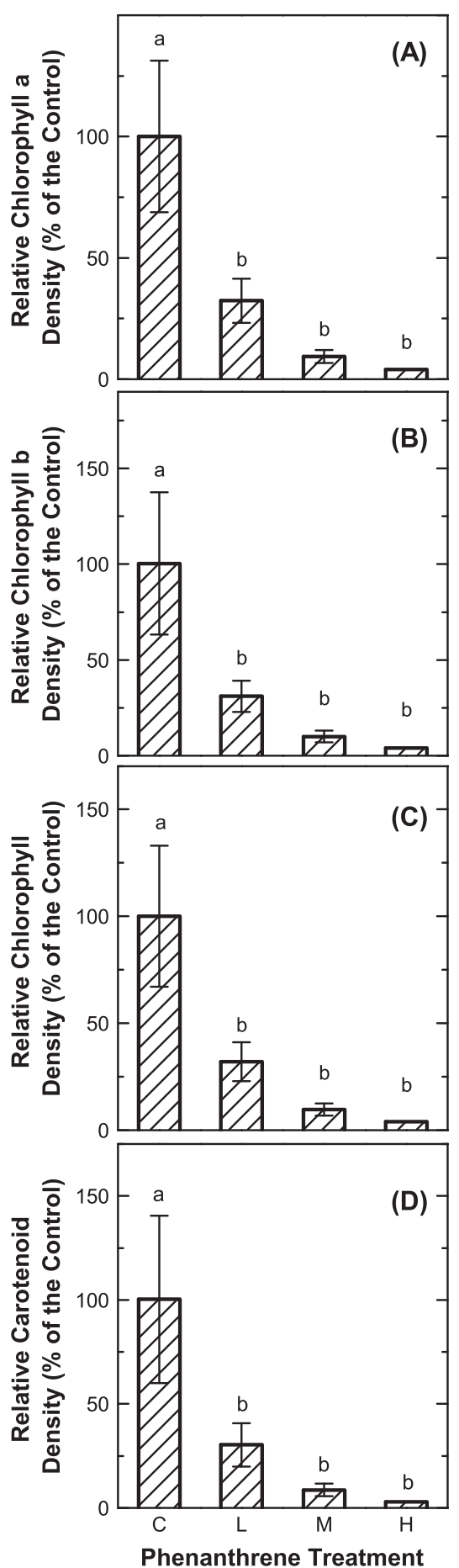

Fig. 5. Effects of phenanthrene on the canopy photosynthetic pigment densities of Suaeda salsa. The values are means \pm standard errors $(n=3)$. Other descriptions are the same as Fig. 3. The real values are presented in Table 2.

foliar or canopy red reflectance could respond to stress with a consistent increase (Carter, 1993; Smith et al., 2004). However, the canopy reflectance of seepweed community at $680 \mathrm{~nm}$ in treatment $\mathrm{M}$ was only slightly higher compared with that in treatment L (Fig. 6B), although the canopy chlorophyll density of seepweed responded to phenanthrene with an obvious trend (Fig. 5C), showing a significantly negative association with canopy reflectance at $680 \mathrm{~nm}$ (Fig. 7A). Standing litter in the view of spectroradiometer might be one possible reason for the small difference between treatment $\mathrm{L}$ and $\mathrm{M}$ (Fig. 1H-I) (Asner, 1998).

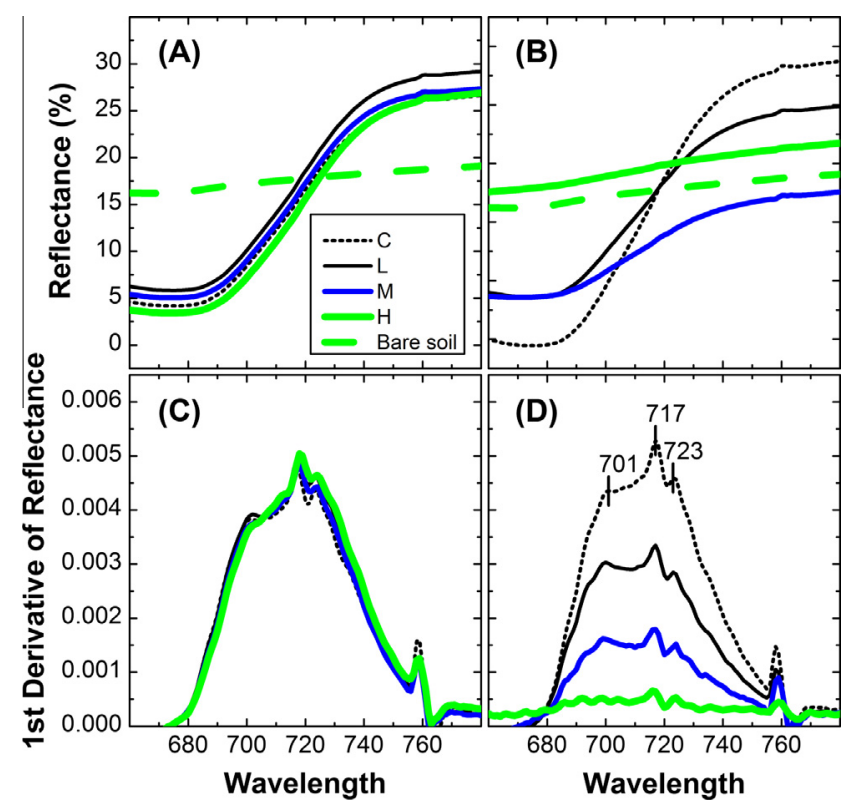

Fig. 6. Effects of phenanthrene on the canopy spectral properties of Phragmites australis community and Suaeda salsa community. (A) Reflectance of $P$. australis community. (B) Reflectance of $S$. salsa community. (C) First derivative of reflectance of $P$. australis community. (D) First derivative of reflectance of $S$. salsa community. The numbers and vertical lines in the panel $\mathrm{D}$ indicate the peaks. Other descriptions (the letters C, L, M, H in the legend) are the same as Fig. 1.
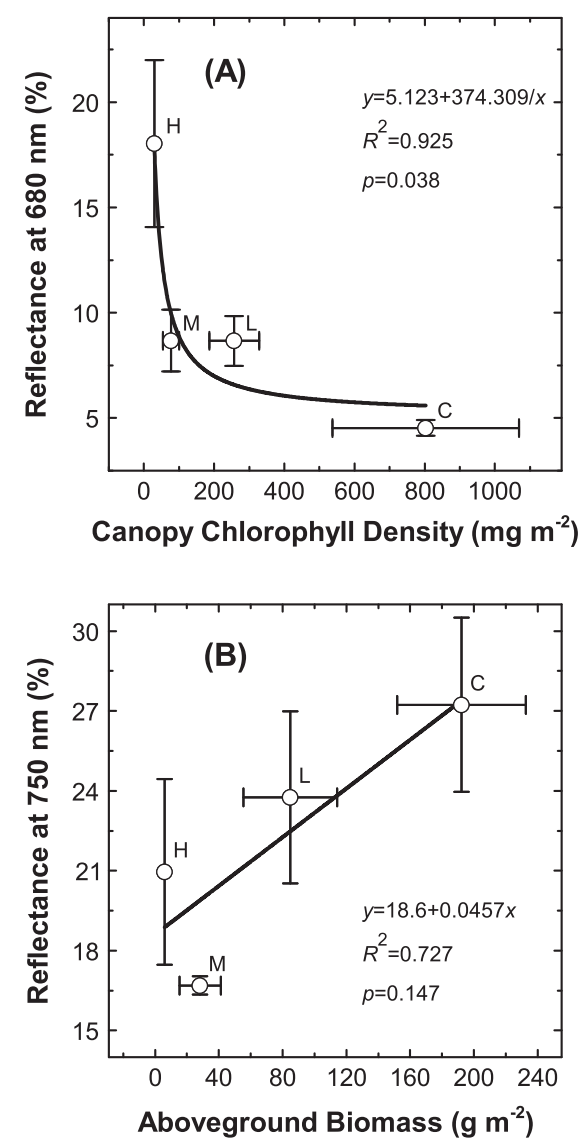

Fig. 7. Relationships between canopy reflectance of Suaeda salsa community and canopy chlorophyll density (A) and aboveground biomass (B) of S. salsa. The error bars indicate the standard errors of means. Other description (the letters $C, \mathrm{~L}, \mathrm{M}, \mathrm{H}$ around the data points) are the same as Fig. 1. 
The near-infrared reflectance of plants is positively related to aboveground biomass (Rosso et al., 2005; Thenkabail et al., 2000) and affected by leaf morphology and anatomical properties

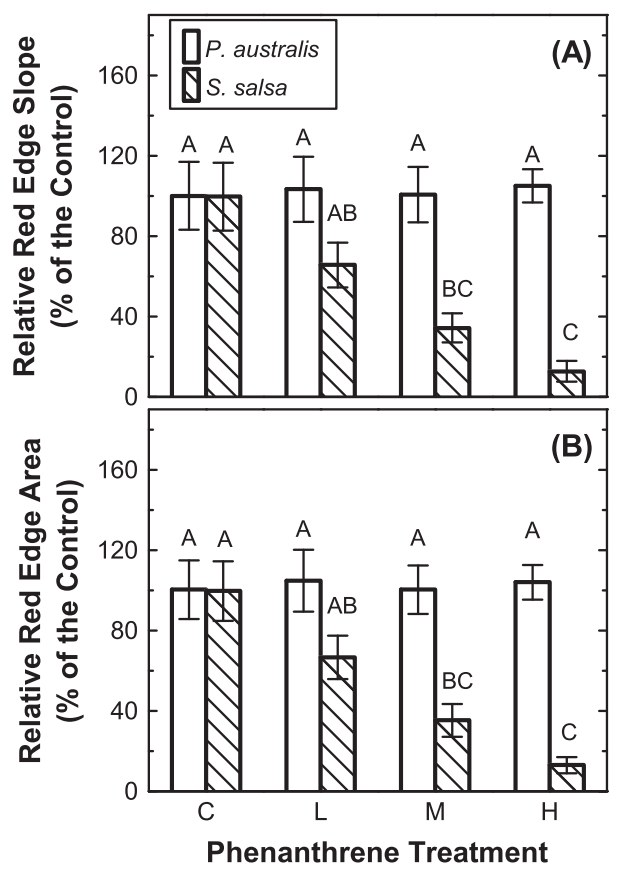

Fig. 8. Effects of phenanthrene on the red edge slope (A) and area (B) of Phragmites australis community and Suaeda salsa community. The values are means \pm standard errors $(n=3)$. Other descriptions are the same as Fig. 3. The real values are presented in Table 2.
(Gates et al., 1965; Woolley, 1971) such as fractions of intercellular spaces (Rosso et al., 2005). Canopy reflectance of near-infrared light generally responds to environmental stress poorly compared with red reflectance, because canopy reflectance is more affected by bare soil (Zhu et al., 2013). In this study, the near-infrared reflectance of bare soil was in a similar range of seepweed community (Fig. 6B). These results provided the evidence for this reason. Dead stems and leaves (Asner, 1998) may also affect the nearinfrared reflectance of plants.

The two canopy spectral behaviors, absorption of red light and leaf internal scattering of near-infrared light, are related to many plant parameters that indicate plant status, including chlorophyll, aboveground biomass and LAI (Filella and Peñuelas, 1994). The red edge is also closely related to chlorophyll fluorescence (Zarco-Tejada et al., 2003), a powerful and widely used technique to detect plant stress (Maxwell and Johnson, 2000). Therefore, the red edge may be a general indicator of plant status by integrating multiple plant responses including biochemistry, physiology, growth and mortality (Schaepman et al., 2009).

The red edge characterized stressed plants more accurately by integrating the variation of red and near-infrared reflectance. Because the first derivative of reflectance from the bare soil is usually close to zero, the derivative analysis will enhance vegetation signals and suppress the effects of bare soils (Demetriades-Shah et al., 1990). Furthermore, the spectral curve of standing litter in the region of the red edge is similar to that of soil in shape and does not contain any notable absorption feature compared with green leaves (Asner, 1998). Therefore, the derivative analysis also could counteract the effects of standing litter. These advantages make the derivative analysis of the red edge perform better compared with the reflectance of red and near-infrared light. This study also found that the red edge parameters, especially red edge area, corresponded consistently with plant parameters (Figs. 8 and 9) and
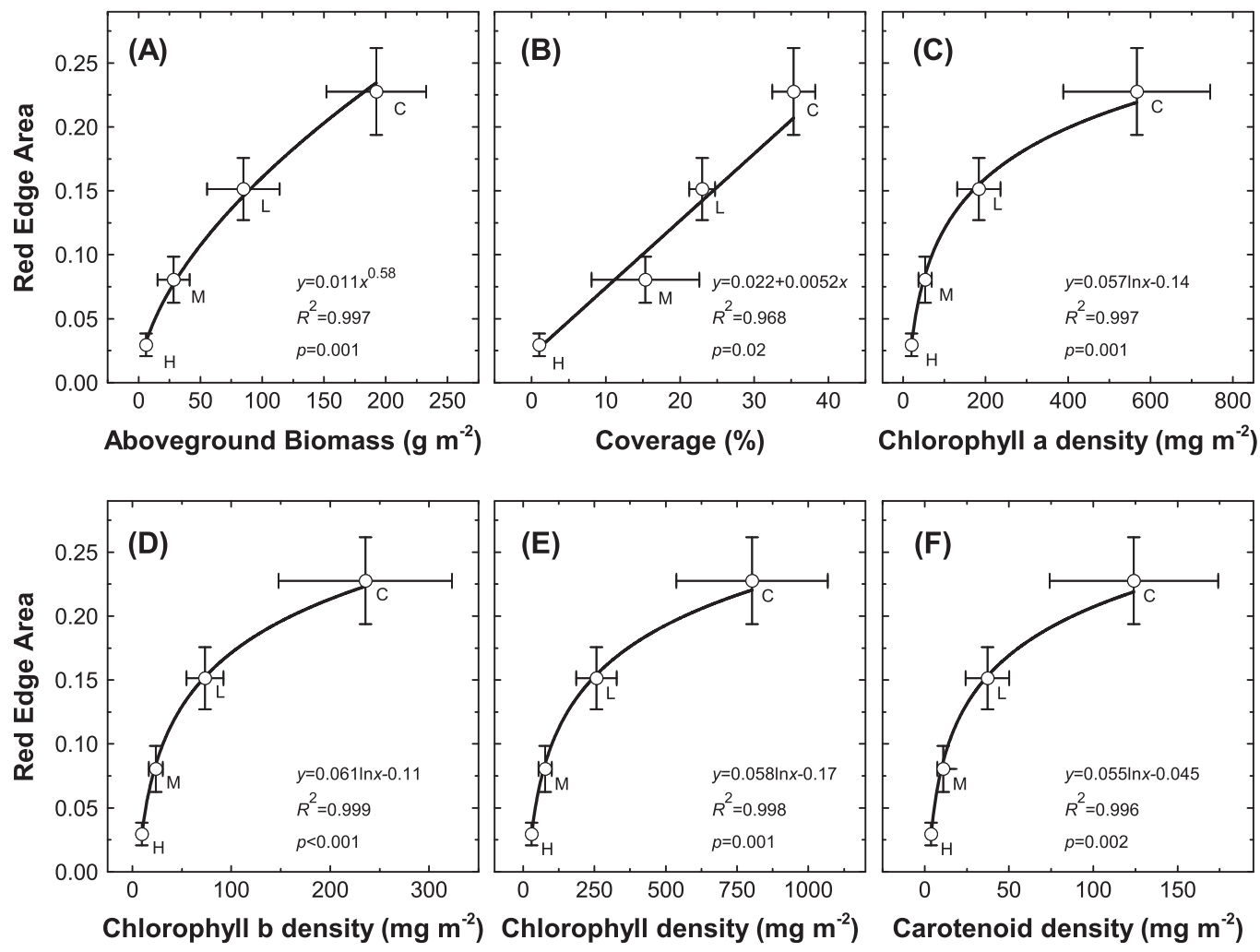

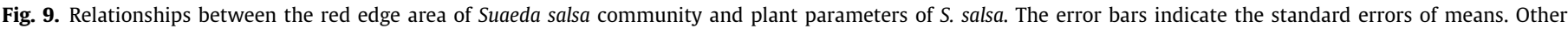
descriptions (the letters $\mathrm{C}, \mathrm{L}, \mathrm{M}, \mathrm{H}$ around the data points) are the same as Fig. 1. 
show potential for the non-destructive monitoring of contaminated plants. Because the spectral changes in the red edge region is the theoretical foundation for the other vegetation indices consisting of red reflectance and near-infrared reflectance, the utility of vegetation indices to monitor vegetation response to phenanthrene show great promise and should be investigated together with the red edge parameters at a larger extent.

Two or more peaks often exist in the derivative spectra. Two peaks at ca. 700 and $725 \mathrm{~nm}$ were first identified (Goetz et al., 1985). Three peaks were also found by different researchers (Clevers et al., 2004). Furthermore, four peaks at 702, 718, 725 and $735 \mathrm{~nm}$ were identified between 680 and $750 \mathrm{~nm}$ (Smith et al., 2004). We also found three peaks located at 700, 717 and $723 \mathrm{~nm}$. The small difference in the positions of the peaks (for example, $723 \mathrm{~nm}$ and $725 \mathrm{~nm}$ found in different studies) might be caused by the selection of derivative gap in the calculation of the first derivative. The presence and utility of these peaks requires further investigation.

\section{Conclusions}

In this experiment of 3 months, phenanthrene had different effects on the reed community and seepweed community. For reed ecosystem, different treatments showed no significant difference in measured parameters at the end of experiment. For seepweed ecosystem, the addition of phenanthrene led to the increased mortality of seepweed. However, the remains of seepweed finally recovered and show no difference in leaf photosynthetic pigment concentrations. The decrease of live stem density, biomass and coverage of seepweed associated with the increase of its mortality could explain the decrease of canopy pigment density. Therefore, the changes of biomass and coverage mediated the relationship between spectral changes and canopy pigment density. The spectral parameters (red edge slope and area) responded to the phenanthrene, consistently with the plant parameters. These results demonstrated that remote sensing has the potential for monitoring pollution-affected vegetation and the images interpretation of remote sensing should be validated with field data to correctly identify factors that were associated with the spectral change.

\section{Acknowledgments}

This work was supported by the National Key Technology R\&D Program of China (2008BAC43B01). We also greatly appreciate the anonymous reviewers for the insightful comments.

\section{Appendix A. Supplementary material}

Supplementary data associated with this article can be found, in the online version, at http://dx.doi.org/10.1016/j.marpolbul.2014. 06.046 .

\section{References}

Asner, G.P., 1998. Biophysical and biochemical sources of variability in canopy reflectance. Remote Sens. Environ. 64, 234-253.

Ayanu, Y.Z., Conrad, C., Nauss, T., Wegmann, M., Koellner, T., 2012. Quantifying and mapping ecosystem services supplies and demands: a review of remote sensing applications. Environ. Sci. Technol. 46, 8529-8541.

Broge, N.H., Leblanc, E., 2000. Comparing prediction power and stability of broadband and hyperspectral vegetation indices for estimation of green leaf area index and canopy chlorophyll density. Remote Sens. Environ. 76, 156-172.

Camacho, M., Boada, L.D., Orós, J., Calabuig, P., Zumbado, M., et al., 2012. Comparative study of polycyclic aromatic hydrocarbons (PAHs) in plasma of Eastern Atlantic juvenile and adult nesting loggerhead sea turtles (Caretta caretta). Mar. Pollut. Bull. 64, 1974-1980.
Carter, G.A., 1993. Responses of leaf spectral reflectance to plant stress. Am. J. Bot. 80, 239-243.

Cho, M.A., Skidmore, A.K., 2006. A new technique for extracting the red edge position from hyperspectral data: the linear extrapolation method. Remote Sens. Environ. 101, 181-193.

Clevers, J.G.P.W., Kooistra, L., Salas, E.A.L., 2004. Study of heavy metal contamination in river floodplains using the red-edge position in spectroscopic data. Int. J. Remote Sens. 25, 1-13.

Demetriades-Shah, T.H., Steven, M.D., Clark, J.A., 1990. High resolution derivative spectra in remote sensing. Remote Sens. Environ. 33, 55-64.

Fauzi, A., Skidmore, A.K., van Gils, H., Schlerf, M., Heitkönig, I.M.A., 2013. Shrimp pond effluent dominates foliar nitrogen in disturbed mangroves as mapped using hyperspectral imagery. Mar. Pollut. Bull. 76, 42-51.

Filella, I., Peñuelas, J., 1994. The red edge position and shape as indicators of plant chlorophyll content, biomass and hydric status. Int. J. Remote Sens. 15, 14591470.

Gan, S., Lau, E.V., Ng, H.K., 2009. Remediation of soils contaminated with polycyclic aromatic hydrocarbons (PAHs). J. Hazard. Mater. 172, 532-549.

Gates, D.M., Keegan, H.J., Schleter, J.C., Weidner, V.R., 1965. Spectral properties of plants. Appl. Opt. 4, 11-20.

Goetz, A.F.H., Vane, G., Solomon, J.E., Rock, B.N., 1985. Imaging spectrometry for earth remote sensing. Science 228, 1147-1153.

Haritash, A.K., Kaushik, C.P., 2009. Biodegradation aspects of polycyclic aromatic hydrocarbons (PAHs): a review. J. Hazard. Mater. 169, 1-15.

Horler, D.N.H., Dockray, M., Barber, J., 1983. The red edge of plant leaf reflectance Int. J. Remote Sens. 4, 273-288.

Hunter, P.D., Tyler, A.N., Gilvear, D.J., Willby, N.J., 2009. Using remote sensing to aid the assessment of human health risks from blooms of potentially toxic cyanobacteria. Environ. Sci. Technol. 43, 2627-2633.

Judy, C.R., Graham, S.A., Lin, Q.X., Hou, A.X., Mendelssohn, I.A., 2014. Impacts of Macondo oil from Deepwater Horizon spill on the growth response of the common reed Phragmites australis: a mesocosm study. Mar. Pollut. Bull. 79, 6976.

Knipling, E.B., 1970. Physical and physiological basis for the reflectance of visible and near-infrared radiation from vegetation. Remote Sens. Environ. $1,155-159$.

Konica Minolta Sensing Inc., 2003. SPAD-502 User Guide. Osaka, Japan.

Kooistra, L., Salas, E.A.L., Clevers, J.G.P.W., Wehrens, R., Leuven, R.S.E.W., et al., 2004. Exploring field vegetation reflectance as an indicator of soil contamination in river floodplains. Environ. Pollut. 127, 281-290.

Lichtenthaler, H.K., 1987. Chlorophylls and carotenoids: pigments of photosynthetic biomembranes. Methods Enzymol. 148, 350-382.

Lin, Q.X., Mendelssohn, I.A., 2012. Impacts and recovery of the Deepwater Horizon oil spill on vegetation structure and function of coastal salt marshes in the northern Gulf of Mexico. Environ. Sci. Technol. 46, 3737-3743.

Manzo, C., Salvini, R., Guastaldi, E., Nicolardi, V., Protano, G., 2013. Reflectance spectral analyses for the assessment of environmental pollution in the geothermal site of Mt. Amiata (Italy). Atmos. Environ. 79, 650-665.

Maxwell, K., Johnson, G.N., 2000. Chlorophyll fluorescence-a practical guide. J. Exp. Bot. 51, 659-668.

Mishra, D.R., Cho, H.J., Ghosh, S., Fox, A., Downs, C., et al., 2012. Post-spill state of the marsh: remote estimation of the ecological impact of the Gulf of Mexico oil spill on Louisiana Salt Marshes. Remote Sens. Environ. 118, 176-185.

Mitchell, J.J., Glenn, N.F., Sankey, T.T., De Wayne, R., Derryberry, D.R., et al., 2012 Remote sensing of sagebrush canopy nitrogen. Remote Sens. Environ. 124, 217 223.

Nascimbene, J., Tretiach, M., Corana, F., Lo Schiavo, F., Kodnik, D., et al., 2014. Patterns of traffic polycyclic aromatic hydrocarbon pollution in mountain areas can be revealed by lichen biomonitoring: a case study in the Dolomites (Eastern Italian Alps). Sci. Total Environ. 475, 90-96.

Newete, S.W., Erasmus, B.F.N., Weiersbye, I.M., Cho, M.A. Byrne, M.J., 2014 Hyperspectral reflectance features of water hyacinth growing under feeding stresses of Neochetina spp. and different heavy metal pollutants. Int. J. Remote Sens. 35, 799-817.

Nie, M., Zhang, X.D., Wang, J.Q., Jiang, L.F., Yang, J., et al., 2009. Rhizosphere effects on soil bacterial abundance and diversity in the Yellow River deltaic ecosystem as influenced by petroleum contamination and soil salinization. Soil Biol Biochem. 41, 2535-2542.

Nie, M., Wang, Y.J., Yu, J.Y., Xiao, M., Jiang, L.F., et al., 2011. Understanding plantmicrobe interactions for phytoremediation of petroleum-polluted soil. PLoS ONE 6, e17961.

Pezeshki, S.R., Hester, M.W., Lin, Q., Nyman, J.A., 2000. The effects of oil spill and clean-up on dominant US Gulf coast marsh macrophytes: a review. Environ. Pollut. 108, 129-139.

Rosso, P.H., Pushnik, J.C., Lay, M., Ustin, S.L., 2005. Reflectance properties and physiological responses of Salicornia virginica to heavy metal and petroleum contamination. Environ. Pollut. 137, 241-252.

Schaepman, M.E., Ustin, S.L., Plaza, A.J., Painter, T.H., Verrelst, J., et al., 2009. Earth system science related imaging spectroscopy - an assessment. Remote Sens. Environ. 113, S123-S137.

Smith, K.L., Steven, M.D., Colls, J.J., 2004. Use of hyperspectral derivative ratios in the red-edge region to identify plant stress responses to gas leaks. Remote Sens. Environ. 92, 207-217.

Splajt, T., Ferrier, G., Frostick, L.E., 2003. Monitoring of landfill leachate dispersion using reflectance spectroscopy and ground-penetrating radar. Environ. Sci. Technol. 37, 4293-4298. 
Thenkabail, P.S., Smith, R.B., De Pauw, E., 2000. Hyperspectral vegetation indices and their relationships with agricultural crop characteristics. Remote Sens. Environ. 71, 158-182.

Thenkabail, P.S., Enclona, E.A., Ashton, M.S., van der Meer, B., 2004. Accuracy assessments of hyperspectral waveband performance for vegetation analysis applications. Remote Sens. Environ. 91, 354-376.

Ullah, S., Skidmore, A.K., Naeem, M., Schlerf, M., 2012. An accurate retrieval of leaf water content from mid to thermal infrared spectra using continuous wavelet analysis. Sci. Total Environ. 437, 145-152.

United States Environmental Protection Agency, 2007. Method 8270D Semivolatile organic compounds by gas chromatography/mass spectrometry (GC/MS). Washington, DC, <www.epa.gov/osw/hazard/testmethods/sw846/pdfs/ 8270d.pdf>. (Accessed 23.06.14).

Ustin, S.L., Gitelson, A.A., Jacquemoud, S., Schaepman, M., Asner, G.P., et al., 2009 Retrieval of foliar information about plant pigment systems from high resolution spectroscopy. Remote Sens. Environ. 113, S67-S77.

Wang, C.Y., Du, J.G., Gao, X.L., Duan, Y., Sheng, Y.Q., 2011. Chemical characterization of naturally weathered oil residues in the sediment from Yellow River Delta, China. Mar. Pollut. Bull. 62, 2469-2475.

Woolley, J.T., 1971. Reflectance and transmittance of light by leaves. Plant Physiol. 47, 656-662.
Wu, Y.Z., Chen, J., Ji, J.F., Tian, Q.J., Wu, X.M., 2005. Feasibility of reflectance spectroscopy for the assessment of soil mercury contamination. Environ. Sci. Technol. 39, 873-878.

Yi, Q.X., Huang, J.F., Wang, F.M., Wang, X.Z., Liu, Z.Y., 2007. Monitoring rice nitrogen status using hyperspectral reflectance and artificial neural network. Environ. Sci. Technol. 41, 6770-6775.

Yu, J.B., Kan, X.Y., Wang, X.H., Han, G.X., Guan, B., et al., 2012. Simulative study on effects of petroleum contamination on seedling growth of Phragmites australis and Suaeda salsa in coastal wetland of Yellow River Delta. Sci. Geogr. Sin. 32, 1254-1261.

Zarco-Tejada, P.J., Pushnik, J.C., Dobrowski, S., Ustin, S.L., 2003. Steady-state chlorophyll a fluorescence detection from canopy derivative reflectance and double-peak red-edge effects. Remote Sens. Environ. 84, 283-294.

Zhang, F., John, R., Zhou, G.S., Shao, C.L., Chen, J.Q., 2014. Estimating canopy characteristics of Inner Mongolia's grasslands from field spectrometry. Remote Sens. 6, 2239-2254.

Zhu, L.H., Zhao, X.C., Lai, L.M., Wang, J.J., Jiang, L.H., et al., 2013. Soil TPH concentration estimation using vegetation indices in an oil polluted area of eastern China. PLoS ONE 8, e54028. 